\title{
Preclusión procesal y principio de igualdad de armas en el proceso penal peruano*
}

\author{
César Bravo Zorrilla \\ cebravozlla@gmail.com \\ https://orcid.org/0000-0002-0481-8040 \\ Universidad César Vallejo \\ Trujillo - Perú
}

\section{RESUMEN}

Este trabajo tuvo como objetivo analizar de qué manera se relacionan los principios de preclusión procesal e igualdad de armas en el proceso penal peruano. Con tal propósito se realizó una investigación teórica de enfoque cualitativo y siguiendo el diseño de teoría fundamentada. Se utilizaron como técnicas de recolección de datos el análisis de documentos y la entrevista. Los resultados obtenidos muestran que el principio de preclusión ordena y organiza el contradictorio procesal, a través de las etapas y fases del proceso penal; mientras que el principio de igualdad de armas persigue garantizar a las partes iguales posibilidades para el ejercicio de derechos y facultades previstas en la legislación procesal penal. Como conclusión general se determinó que los principios de preclusión procesal e igualdad de armas son dos figuras jurídicas estrechamente vinculadas, dado que, en su condición de principios, comparten la misma naturaleza, es decir, son mandatos de optimización; ambos principios se encuentran regulados en el Código Procesal Penal; tienen fundamento constitucional y han sido abordados por la jurisprudencia penal de la Corte Suprema de Justicia del Perú.

Palabras clave: preclusión procesal; igualdad de armas; proceso penal.

\footnotetext{
* El artículo presenta hallazgos parciales del estudio "Preclusión procesal y principio de igualdad de armas, Corte Suprema del Perú, 2015-2020", tesis para obtener el Grado Académico de Maestro en Derecho Penal y Procesal Penal en la Universidad César Vallejo de Trujillo, Perú.
} 


\title{
Procedural preclusion and the principle of equality of arms in the Peruvian criminal process
}

\begin{abstract}
This study aimed to analyze how the principles of procedural preclusion and equality of arms are related in the Peruvian criminal process. For this purpose, a theoretical research with a qualitative approach was carried out and following the grounded theory design. Document analysis and interview were used as data collection techniques. The results obtained show that the preclusion principle orders and organizes the procedural contradictory, through the stages and phases of the criminal process; while the principle of equality of arms seeks to guarantee equal possibilities for the exercise of rights and powers provided for in criminal procedural legislation. As a general conclusion, it was determined that the principles of procedural preclusion and equality of arms are two closely related legal figures, given that, as principles, they share the same nature, that is, they are optimization mandates; Both principles are regulated in the Criminal Procedure Code; They have a constitutional basis and have been addressed by the criminal jurisprudence of the Supreme Court of Justice of Peru.
\end{abstract}

Keywords: procedural preclusion, principle of equality of arms, criminal process.

Artículo recibido: 02 enero 2022 Aceptado para publicación: 28 enero 2022 Correspondencia: cebravozlla@gmail.com Conflictos de Interés: Ninguna que declarar 


\section{INTRODUCCIÓN}

En el proceso penal existen ciertos principios que son de mucha importancia y que constituyen los ejes centrales del modelo acusatorio adversarial. Estos principios, entre otros, que constituyen el contenido esencial del debido proceso penal, son el de preclusión procesal y el de igualdad de armas, ambos tendientes a compensar el desequilibrio que se presenta entre la fiscalía y la defensa, ya sea durante las etapas previas al juicio o durante el desarrollo del mismo, pudiendo darse este último ante un juzgado unipersonal o ante un juzgado colegiado, según el tipo de delitos o por la gravedad de los mismos.

Desde esta perspectiva, Alvarado (2018) afirma que el principio de preclusión procesal establece un orden secuencial para el desarrollo de los actos procesales dentro de las etapas y fases del proceso penal. Asimismo, esta figura procesal puede ser conceptualizada de dos maneras: en primer lugar, como un sistema que organiza y ordena el contradictorio procesal, y, en segundo lugar, como una categoría que establece los supuestos en los que opera la preclusión dentro de cada momento procesal (p. 340).

Por su parte, Beriain y Pérez (2019) refieren que la igualdad de armas como principio procesal penal garantiza que las partes dispongan de las mismas posibilidades procesales en los diferentes momentos de la actividad probatoria, a fin de lograr el resultado que se pretende obtener desde la perspectiva de cada una de las partes. En otras palabras, la igualdad de armas asegura que las partes procesales ostenten los mismos derechos y que afronten las mismas cargas, en igualdad de condiciones, sin que existan privilegios o desigualdades que favorezcan a una de ellas (p. 551).

A nivel internacional se puede observar que aun cuando en muchos países no se usan los mismos términos para referirse a las categorías de preclusión procesal e igualdad de armas, es posible referirnos a ellas sobre la base de ciertos criterios relacionados con su naturaleza jurídica. En el caso de Colombia, de acuerdo con la legislación procesal penal vigente y la jurisprudencia penal de la Corte Constitucional, se deduce que la preclusión es incompatible con el principio de igualdad procesal, toda vez que se trata de una figura cuya titularidad le corresponde casi de forma exclusiva a la fiscalía, excluyendo a la defensa la posibilidad de solicitarla, dado que en la actualidad, su acceso es restringido, constituyendo un menoscabo no justificado al principio de igualdad entre las partes (Acosta, 2018, p. 136). 
En países como España, según Acosta (2018), la categoría de la preclusión no aparece como tal, sino que en la legislación procesal penal se establece el sobreseimiento con sus respectivas causales, las cuales producen distintos efectos. Así, se establece que, al término de la investigación, la defensa puede participar para que, si lo considera pertinente, se pronuncie respecto del sobreseimiento (pp. 131-132).

De igual forma, en México, se observa ciertas restricciones en la aplicación del principio de igualdad procesal, tal es el caso de los investigados o procesados por delitos graves o en los casos de personas acusadas por delincuencia organizada, quienes no gozan de las mismas oportunidades procesales para ofrecer y actuar pruebas. En este sentido, se puede afirmar que en el proceso penal mexicano no se respeta la igualdad entre las partes, y, por ende, se produce un menoscabo a los derechos fundamentales de las referidas personas (Santacruz, 2017, p. 141).

En el caso de Perú, por mandato constitucional, el Ministerio Público tiene la responsabilidad de conducir la investigación del delito, así como también la representación de la sociedad en juicio (Rioja, 2019, p. 647). Dado que la fiscalía ostenta la exclusividad de la persecución penal, olvida su rol constitucional de vigilar la legalidad de sus actuaciones. Es más, en la Etapa de Investigación, el fiscal no tiene un verdadero contradictor en igualdad de condiciones, y al no haber equilibrio tampoco existe igualdad de partes. Las facultades otorgadas por ley a la defensa, teóricamente similares a las de la Fiscalía, por falta de medios para hacerlas efectivas, confirman el desequilibrio y la desproporción (Ortiz, 2010, pp. 57-58).

Si bien es cierto, el artículo IX del Título Preliminar del Código Procesal Penal, al referirse al derecho de defensa, establece que toda persona tiene derecho a participar en igualdad de condiciones en la actividad probatoria; sin embargo, en la realidad se observan muchos casos en los que únicamente son prerrogativas de la fiscalía, más no así de la defensa. Así, por ejemplo, el fiscal tiene facultades para realizar allanamientos o incautación de bienes, más no así la defensa. El fiscal puede formular acusación directa o impugnar decisiones judiciales que afectan al procesado, generando un desequilibrio en la igualdad de partes.

Entre las múltiples causas del problema, se menciona que la fiscalía conserva frente a la defensa algunos privilegios que por mandato legal le corresponde únicamente al órgano persecutor del delito; la defensa del acusado tiene una esfera de investigación restringida, 
en comparación con la de la Fiscalía, quien puede ejecutar actos de investigación, y es más, posee facultades coercitivas que le confiere la norma procesal penal; y en nuestro sistema procesal penal, el fiscal conduce la investigación del delito, disponiendo los actos de indagación que considere pertinentes.

Así las cosas, el problema, objeto del presente estudio, se formuló en los siguientes términos: ¿De qué manera se relacionan los principios de preclusión procesal e igualdad de armas en la jurisprudencia penal de la Corte Suprema de Justicia del Perú? Para responder a esta interrogante se planteó como objetivo general analizar de qué manera se relacionan los principios de preclusión procesal e igualdad de armas en la jurisprudencia penal de la Corte Suprema de Justicia del Perú, en el periodo 2015 al 2020. Y, como objetivos específicos, analizar la regulación del principio de preclusión en el Código Procesal Penal peruano; analizar los fundamentos que rigen el principio de preclusión en el proceso penal peruano; analizar la aplicabilidad del principio de preclusión en el proceso penal peruano a partir de la jurisprudencia nacional; analizar la regulación del principio de igualdad de armas en el Código Procesal Penal peruano; analizar los fundamentos que rigen el principio de igualdad de armas en el proceso penal peruano y, analizar la aplicabilidad del principio de igualdad de armas en el proceso penal peruano a partir de la jurisprudencia nacional.

La investigación se justifica desde el punto de vista teórico, puesto que ha permitido conocer las interrelaciones existentes entre los principios de preclusión procesal e igualdad de armas en el proceso penal, de modo que los hallazgos encontrados son automáticamente incorporados al campo gnoseológico de la ciencia jurídica. Desde el punto de vista práctico, los resultados obtenidos permiten a los operadores jurídicos reflexionar en torno a la aplicación de los principios procesales preclusión procesal e igualdad de armas, en aras de dotar a las partes de un sistema garantista y bajo el cobijo del principio de contradicción.

Metodológicamente, la investigación se justifica porque se enmarca en un diseño metodológico propio del enfoque cualitativo, esto es, en el diseño de Teoría Fundamentada, el cual se orienta a generar teoría a partir de datos empíricos. Además, porque permitió diseñar instrumentos para la recolección de datos y posteriormente, aplicarlos a los participantes seleccionados mediante el muestreo teórico por saturación 
de datos, y la sistematización de experiencias hizo posible dar respuesta al objetivo principal de la investigación.

\section{MATERIALES Y MÉTODOS}

Por su finalidad, la presente investigación es básica, conocida también como pura, teórica o fundamental, cuyo objetivo es obtener nuevos conocimientos sin un fin práctico específico e inmediato (Fernández et al., 2015, p. 12). Este tipo de investigación busca ampliar y profundizar el caudal de conocimientos científicos existentes acerca de la realidad. Según su enfoque, esta investigación es cualitativa. En palabras de Aranzamendi (2015), la investigación jurídica cualitativa se orienta a describir y comprender una situación relacionada con el Derecho (p. 148).

En el estudio se utilizó el diseño de Teoría Fundamentada, esto es, la construcción de teoría basada en los datos empíricos, siguiendo un procedimiento de análisis inductivo. Según Hernández-Sampieri y Mendoza (2018), esta teoría tiene como propósito formular explicaciones respecto a una acción, fenómeno o proceso, circunscrito a un contexto determinado y desde la óptica de los participantes (p. 526). A decir de Bonilla-García y López-Suárez (2016), la Teoría Fundamentada es un método de investigación, donde el investigador se involucra en el proceso, a fin de comprender mejor el fenómeno objeto de estudio (p. 305). En este modelo se identifican cinco procesos a seguir: recolección de datos, codificación abierta, codificación axial, codificación selectiva y creación de teoría (Mercado et al., 2019, p. 112).

El escenario de estudio estuvo constituido por la Corte Suprema de Justicia del Perú, y específicamente por el Portal Web del Poder Judicial, de donde se descargaron un total de ocho sentencias emitidas por las salas penales de la Corte Suprema de Justicia del Perú, correspondientes a los años 2015 al 2020. Asimismo, en dicho estudio participaron ocho abogados especialistas en el nuevo sistema procesal penal. La selección de la muestra no probabilística se realizó a partir del muestreo teórico. A su vez, el criterio para fijar el tamaño de la muestra fue el de saturación de las categorías investigadas.

La técnica utilizada para el recojo de la información fue el análisis de documentos, a partir del análisis de fuentes doctrinales, análisis de normas nacionales y análisis de sentencias. Esta técnica nos permitió la revisión, el análisis y la interpretación de las diversas fuentes documentales y que estuvieron referidas directamente a las categorías de estudio. De igual forma, se utilizó la técnica de la entrevista para el recojo de información de parte de 
abogados litigantes en el sistema penal acusatorio. Los instrumentos utilizados fueron la guía de análisis de fuentes doctrinales, la guía de análisis de normas nacionales y la guía de análisis de sentencias. Asimismo, se utilizó la guía de entrevista, compuesta por 12 ítems en forma de preguntas abiertas semiestructuradas. Siguiendo a Hernández-Sampieri y Mendoza (2018), otro instrumento que se empleó en la recolección de los datos cualitativos lo fue también el mismo investigador, con el auxilio de técnicas como la entrevista y el análisis de documentos (p. 443).

Siguiendo los pasos de la Teoría Fundamentada, luego de recolectados los datos de las entrevistas, se procedió a su organización, codificación, categorización, y finalmente se realizó la triangulación de los mismos. Por su parte, los datos obtenidos de las fuentes documentales fueron analizados en tres bloques: análisis de fuentes doctrinales, análisis de normas nacionales y análisis de la jurisprudencia nacional; concluyendo con la triangulación respectiva.

Para el análisis cualitativo de los datos recogidos mediante la técnica del análisis documental, se recurrió al uso de métodos utilizados por la ciencia jurídica, que a decir de Villabella (2015), estos son el método de análisis-síntesis, el método inductivo, el método de análisis de contenido y el método hermenéutico-jurídico (p. 944). Asimismo, se utilizaron el método de comparación constante para generar las categorías conceptuales, y el método de saturación de la información, que permitió al investigador ir avanzando en la recogida de datos hasta encontrar información que se va repitiendo en todos los segmentos examinados.

Por último, la presente investigación tuvo en consideración los aspectos éticos implicados en el estudio, tales como la originalidad, la confidencialidad y el anonimato. La ética, además de estar presente en todo investigador, debe ser observada a través de los estilos normativos empleados para la citación y referenciación. En este orden de ideas, se ha tenido especial cuidado al momento de citar a los autores y en la elaboración de las referencias (Salazar et al., 2018, p. 309). Asimismo, el investigador ha tenido en cuenta ciertos requisitos en el diseño del estudio, en el recojo de datos y en la divulgación de los resultados del estudio. Estos requisitos están relacionados con el manejo de la confidencialidad, el conocimiento informado y con los posibles riesgos de los que pudieron o pueden ser objeto los participantes del estudio (Noreña et al., 2012, pp. 269270. 


\section{RESULTADOS Y DISCUSIÓN}

Los resultados derivados del análisis de las fuentes doctrinales, análisis de normas nacionales y del análisis de la jurisprudencia nacional, indicaron que las categorías preclusión procesal y principio de igualdad de armas presentan referencia explícita en el Código Procesal Penal peruano; tienen fundamento constitucional y fundamento procesal penal, así como también han sido abordadas por la jurisprudencia penal de la Corte Suprema de Justicia del Perú.

Con respecto a la entrevista semiestructurada que se les aplicó a ocho abogados litigantes, una vez recogida la información, se procedió a realizar la organización de los datos en una matriz de codificación, procediendo luego a la codificación teórica en sus formas abierta, axial y selectiva. La codificación abierta permitió expresar en forma de conceptos las respuestas dadas por los entrevistados; por su parte, mediante la codificación axial se procedió a filtrar las categorías surgidas en la codificación abierta, tratando de reorganizar la información creando nuevas relaciones; por último, la codificación selectiva consistió en seleccionar en cada caso una categoría central en torno a la que se organizan, se integran y se agrupan el resto de categorías. Cabe resaltar que la entrevista realizada a los abogados penalistas constó de 12 preguntas orientadas a indagar sobre el conocimiento que se tiene respecto de la regulación normativa, los fundamentos y la aplicabilidad de las categorías objeto de estudio.

Del análisis realizado surgieron las categorías y subcategorías, a saber:

- Categoría 1: Preclusión procesal, con las subcategorías: regulación normativa, requisitos, tipos, fundamento y tratamiento jurisprudencial.

- Categoría 2: Principio de igualdad de armas, con las subcategorías: regulación normativa, fundamento, dimensiones y tratamiento jurisprudencial.

Posteriormente, con los resultados del análisis documental se generó una matriz descriptiva donde se muestra la triangulación del marco doctrinario, el marco jurídico y el marco jurisprudencial, para cada una de las categorías objeto de estudio. De forma similar, se configuró una matriz para los resultados de las entrevistas, donde se muestran las preguntas del instrumento, las respuestas dadas por los abogados entrevistados, las analogías y las diferencias encontradas, así como las conclusiones del investigador.

La triangulación posibilita dar validez a los datos de tipo cualitativo, a través de la búsqueda de patrones concurrentes y convergentes que permitan generar una 
interpretación de la situación en estudio, empleando para ello el marco doctrinario, el marco legal y el marco jurisprudencial. A continuación, se presentan las matrices de triangulación, donde se evidencia lo expresado.

\section{Tabla 1}

Triangulación del marco doctrinario, marco jurídico y marco jurisprudencial

\begin{tabular}{|c|c|c|}
\hline \multicolumn{3}{|c|}{ Categoría: Preclusión Procesal } \\
\hline Marco Doctrinario & Marco Jurídico & Marco Jurisprudencial \\
\hline $\begin{array}{l}\text { Según Vallines (2016), } \\
\text { la preclusión es la } \\
\text { extinción de potestades, } \\
\text { derechos o facultades } \\
\text { procesales no } \\
\text { ejercitadas por las partes } \\
\text { involucradas o que } \\
\text { pueden involucrarse en } \\
\text { un proceso penal } \\
\text { determinado (p. 3172). }\end{array}$ & $\begin{array}{lr}\text { El respeto de las formas } \\
\text { procesales } & \text { viene } \\
\text { representado } & \text { por la } \\
\text { garantía de } & \text { legalidad } \\
\text { procesal, } & \text { cuyo } \\
\text { reconocimiento } & \text { se } \\
\text { encuentra en el artículo 138 } \\
\text { de la Constitución Política } \\
\text { del Perú. }\end{array}$ & $\begin{array}{l}\text { Por el principio de preclusión } \\
\text { no es posible cuestionar } \\
\text { defectos procesales de etapas } \\
\text { ya concluidas. } \\
\text { El cuestionamiento a defectos } \\
\text { procesales debe realizarse en } \\
\text { las respectivas etapas } \\
\text { procesales (Corte Suprema de } \\
\text { Justicia del Perú, Casación } \mathrm{N}^{\circ} \\
\text { 1547-2018, 2019). }\end{array}$ \\
\hline $\begin{array}{l}\text { De acuerdo con Vallines } \\
\text { (2016), para que se } \\
\text { produzca la preclusión } \\
\text { se requiere de la } \\
\text { concurrencia de los } \\
\text { cuatro presupuestos } \\
\text { operativos y de una } \\
\text { causal de preclusión que } \\
\text { ha previsto la } \\
\text { normatividad procesal } \\
\text { (p. 3173). }\end{array}$ & $\begin{array}{l}\text { Los actos procesales deben } \\
\text { ser sustanciados bajo los } \\
\text { principios procesales de } \\
\text { legalidad y preclusión, } \\
\text { entre otros (Art. } 6 \text { de la Ley } \\
\text { Orgánica del Poder } \\
\text { Judicial). } \\
\text { Los artículos } 153.2 \text { y } 154.3 \\
\text { del Código Procesal Penal } \\
\text { refieren que no se podrá } \\
\text { retrotraer el proceso a } \\
\text { etapas o periodos ya } \\
\text { precluidas. } \\
\text { En el artículo } 350 \text { del } \\
\text { Código Procesal Penal se } \\
\text { establecen una formalidad } \\
\text { y un límite temporal para el } \\
\text { ofrecimiento de pruebas. }\end{array}$ & $\begin{array}{l}\text { El Fiscal no puede impugnar } \\
\text { por primera vez en los mismos } \\
\text { extremos en una tercera } \\
\text { sentencia, si es que no recurrió } \\
\text { una segunda sentencia, de lo } \\
\text { contrario, se lesionaría el } \\
\text { principio de preclusión } \\
\text { procesal, y se quebrantaría el } \\
\text { principio de igualdad de armas } \\
\text { (Corte Suprema de Justicia del } \\
\text { Perú, Recurso de Nulidad } N^{\circ} \\
\text { 1731-2015, 2016). }\end{array}$ \\
\hline
\end{tabular}




\begin{tabular}{|c|c|c|}
\hline $\begin{array}{l}\text { Según Vallines (2016), } \\
\text { es el principio de } \\
\text { seguridad jurídica el } \\
\text { fundamento de la } \\
\text { preclusión, porque con } \\
\text { esta, el legislador } \\
\text { pretende limitar en el } \\
\text { tiempo la situación de } \\
\text { incertidumbre } \\
\text { inseguridad que genera } \\
\text { el posible ejercicio de } \\
\text { una potestad o facultad } \\
\text { procesal. En efecto, para } \\
\text { poner fin a esta } \\
\text { incertidumbre } \\
\text { dispone, que en cierto } \\
\text { instante el poder } \\
\text { procesal no ejercitado } \\
\text { precluya (p. } 3179 \text { ). } \\
\text { Existen dos tipos de } \\
\text { preclusiones. } \\
\text { primera, la preclusión } \\
\text { absoluta que constituye } \\
\text { la extinción completa de } \\
\text { la facultad para realizar } \\
\text { actos procesales; } \\
\text { mientras que, la } \\
\text { segunda, la preclusión } \\
\text { relativa prevé la } \\
\text { posibilidad de } \\
\text { ejercitarla más adelante, } \\
\text { es decir, existe la } \\
\text { posibilidad de hacerlo } \\
\text { valer en otra instancia, } \\
\text { etapa o fase procesal } \\
\text { (Gandulfo, 2009, pp. } \\
\text { 139-140). }\end{array}$ & $\begin{array}{l}\text { El respeto de las formas } \\
\text { procesales } \\
\text { representado por la } \\
\text { garantía de } \\
\text { procesal, legalidad } \\
\text { reconocimiento } \\
\text { encuentra en el artículo } 138 \\
\text { de la Constitución Política } \\
\text { del Perú, concordante con } \\
\text { el Art. I.2 del Código } \\
\text { Procesal Penal. } \\
\text { El artículo IX.1 del Título } \\
\text { Preliminar concordante } \\
\text { con el inciso } 5 \text { del artículo } \\
29 \text { del Código Procesal } \\
\text { Penal, establece que los } \\
\text { jueces de la investigación } \\
\text { preparatoria } \\
\text { facultados para garantizar } \\
\text { la legalidad procesal y la } \\
\text { igualdad de armas. }\end{array}$ & $\begin{array}{l}\text { En el caso de normas } \\
\text { procesales, la norma que rige } \\
\text { es la que está vigente en el } \\
\text { momento de la intervención } \\
\text { procesal. Una norma posterior } \\
\text { no puede alterar una } \\
\text { configuración procesal } \\
\text { predeterminada, por impedirlo } \\
\text { el principio de preclusión } \\
\text { procesal (Corte Suprema de } \\
\text { Justicia del Perú, Casación }{ }^{\circ} \\
\text { 21-2019, 2020). } \\
\text { Las excepciones deben ser } \\
\text { deducidas y resueltas en las } \\
\text { etapas procesales respectivas; } \\
\text { caso contrario, la oportunidad } \\
\text { precluye (Corte Suprema de } \\
\text { Justicia del Perú, Casación } \mathrm{N}^{\circ} \\
\text { 1618-2018, 2020). } \\
\text { Los formalismos vencibles no } \\
\text { prevalecen sobre el derecho a } \\
\text { la igualdad procesal, salvo que } \\
\text { se afecten derechos de las } \\
\text { partes (Corte Suprema de } \\
\text { Justicia del Perú, Casación } \mathrm{N}^{\circ} \\
864-2016,2017) \text {. } \\
\text { La prisión preventiva puede } \\
\text { solicitarse luego de } \\
\text { formalización } \\
\text { investigación preparatoria, } \\
\text { incluso cuando el procesado } \\
\text { ya fue condenado (Corte } \\
\text { Suprema de Justicia del Perú, } \\
\text { Casación No }{ }^{\circ} \text { 1839-2018, } \\
\text { 2019). }\end{array}$ \\
\hline
\end{tabular}




\begin{tabular}{|c|c|c|}
\hline \multicolumn{3}{|c|}{ Categoría: Principio de Igualdad de Armas } \\
\hline Marco Doctrinario & Marco Jurídico & Marco Jurisprudencial \\
\hline $\begin{array}{lr}\text { En palabras } & \text { de } \\
\text { Santacruz }(2017), \text { el } \\
\text { principio de igualdad } \\
\text { procesal } r \\
\text { entenderse debe } \\
\text { facultades como } \\
\text { prerrogativas atribuidas } \\
\text { a los sujetos del } \\
\text { proceso, a fin de que } \\
\text { permita su participación } \\
\text { efectiva en la actividad } \\
\text { probatoria, así como } \\
\text { para contradecir las } \\
\text { decisiones tomadas por } \\
\text { las autoridades (p. 144). } \\
\text { La igualdad de armas es } \\
\text { un principio que tiene } \\
\text { como finalidad corregir } \\
\text { el desequilibrio que en } \\
\text { la práctica acarrea la } \\
\text { persecución penal para } \\
\text { el imputado (Trejo, } \\
\text { 2015, p. 295). }\end{array}$ & 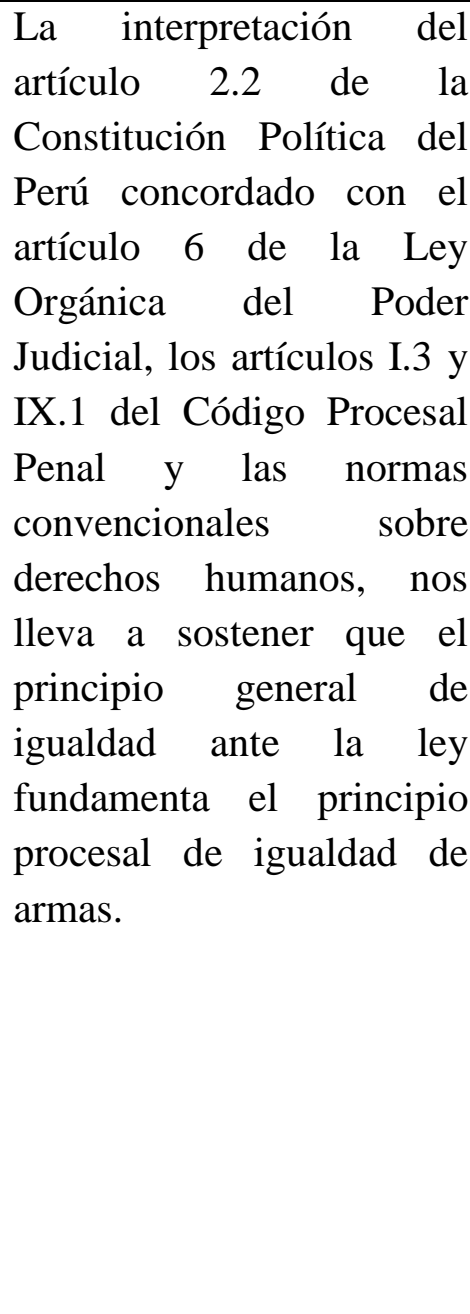 & $\begin{array}{l}\text { Los formalismos vencibles no } \\
\text { prevalecen sobre el derecho a la } \\
\text { igualdad procesal, salvo que se } \\
\text { afecten derechos de las partes } \\
\text { (Corte Suprema de Justicia del } \\
\text { Perú, Casación } \mathrm{N}^{\circ} \text { 864-2016, } \\
2017 \text { ). } \\
\text { Para alegar contravención al } \\
\text { derecho de igualdad ante la ley, } \\
\text { es necesario acreditar que } \\
\text { efectivamente han existido } \\
\text { evidencias de desigualdad de } \\
\text { armas (Corte Suprema de Justicia } \\
\text { del Perú, Recurso de Nulidad N } \\
\text { 1782-2018, 2019). } \\
\text { La variación de la tipificación del } \\
\text { hecho que es objeto de acusación } \\
\text { se da siempre que estas e formule } \\
\text { en las fases previas del juicio } \\
\text { oral, y que se haya concedido la } \\
\text { oportunidad para } \\
\text { contradictorio (Corte Suprema de } \\
\text { Justicia del Perú, Recurso de } \\
\text { Nulidad N }{ }^{\circ} \text { 1232-2016, 2017). }\end{array}$ \\
\hline $\begin{array}{l}\text { Constituye fundamento } \\
\text { del principio de } \\
\text { igualdad de armas el } \\
\text { principio general de } \\
\text { igualdad ante la ley } \\
\text { previsto en el inciso } 2 \\
\text { del artículo } 2^{\circ} \text { de la } \\
\text { Constitución Política } \\
\text { del Perú. } \\
\text { La igualdad de armas } \\
\text { ostenta una doble } \\
\text { dimensión: como } \\
\text { principio objetivo y } \\
\text { como derecho subjetivo. }\end{array}$ & $\begin{array}{l}\text { La igualdad de armas como } \\
\text { principio procesal tiene } \\
\text { fundamento constitucional } \\
\text { (Art. } 2.2 \text { de la Constitución } \\
\text { Política del Perú). }\end{array}$ & $\begin{array}{l}\text { El Fiscal no puede impugnar por } \\
\text { primera vez en los mismos } \\
\text { extremos en una tercera } \\
\text { sentencia, si es que no recurrió } \\
\text { una segunda sentencia, de lo } \\
\text { contrario, se lesionaría el } \\
\text { principio de preclusión procesal, } \\
\text { y se quebrantaría el principio de } \\
\text { igualdad de armas (Corte } \\
\text { Suprema de Justicia del Perú, } \\
\text { Recurso de Nulidad } \mathrm{N}^{\circ} \text { 1731- } \\
\text { 2015, 2016). }\end{array}$ \\
\hline
\end{tabular}

Fuente: Elaboración propia. 
Con respecto al objetivo general que consistió en analizar de qué manera se relacionan los principios de preclusión procesal e igualdad de armas en la jurisprudencia penal de la Corte Suprema de Justicia del Perú, en el periodo 2015 al 2020, los hallazgos muestran que ambas figuras jurídicas se encuentran estrechamente vinculadas, dado que en su condición de principios, comparten la misma naturaleza; presentan referencia explícita en el Código Procesal Penal peruano; tienen fundamento constitucional, así como también han sido abordadas por la jurisprudencia penal de la Corte Suprema de Justicia del Perú. Los resultados están en armonía con las conclusiones de Acosta (2018), quien en su estudio pudo advertir que la fiscalía conserva la potestad casi exclusiva de solicitar la preclusión, lo que acarrea un detrimento injustificado al principio de igualdad de armas (p. 136).

Respecto al primer objetivo específico que consistió en analizar la regulación del principio de preclusión procesal en el Código Procesal Penal peruano, el análisis de los resultados obtenidos de las fuentes documentales como de las entrevistas, ha permitido establecer que el referido Código ofrece una referencia explícita al principio de preclusión en los artículos 153, inciso 2 y 154, inciso 3. A diferencia de lo que ocurre en países como Colombia, donde se ha dejado la titularidad de esta figura, de manera casi exclusiva a la fiscalía (Acosta, 2018, p. 136), en el Perú, esta se activa de pleno derecho, es decir, basta que el proceso penal la origine.

Respecto del segundo objetivo específico que consistió en analizar los fundamentos que rigen el principio de preclusión en el proceso penal peruano, los resultados obtenidos del análisis de las fuentes documentales y de las entrevistas revelan que la preclusión procesal presenta fundamento constitucional recogido en el artículo 138 de la Constitución Política del Perú, que reconoce el principio de legalidad procesal. De igual forma, coincidimos con Vallines (2016), quien sostiene que el principio de preclusión tiene como uno de sus principales fundamentos a la seguridad jurídica, dado que, con esta, es posible establecer ciertos límites a la situación de incertidumbre que se origina por el ejercicio de sus facultades jurídico procesales (p. 3179).

Respecto al tercer objetivo específico, que consistió en analizar la aplicabilidad del principio de preclusión en el proceso penal peruano a partir de la jurisprudencia nacional; los resultados de las entrevistas y los pronunciamientos de la Corte Suprema de Justicia del Perú, a través de la Casación $N^{\circ}$ 21-2019/Arequipa, quinto fundamento jurídico; 
Casación $\mathrm{N}^{\circ}$ 1618-2018-Huaura, fundamento jurídico 9.3, y Casación № 864-2016 Del Santa, han puesto énfasis en la necesidad de que los actos procesales se realicen en el momento fijado por la ley, caso contrario se pierde la oportunidad de realizarlos. Del mismo modo, se ha pronunciado la Corte Suprema de Justicia, a través de la Sala Penal Transitoria en el Recurso de Nulidad $N^{\circ}$ 1731-2015/Cajamarca, quinto fundamento jurídico, y en la Casación N 1457-2018 Nacional. Estos resultados están en armonía con los postulados de Peñaranda et al. (2011), quien considera que la pérdida de derechos o facultades procesales se da por inactividad de los sujetos legitimados (p. 10).

Respecto al cuarto objetivo específico que consistió en analizar la regulación del principio de igualdad de armas en el Código Procesal Penal peruano, los resultados obtenidos tanto de las fuentes documentales como de las entrevistas, ponen de manifiesto que la igualdad de armas como principio procesal penal, se encuentra regulado en el Código Procesal Penal Art. I.3 y IX.1 del Título Preliminar, en los que se destaca que las partes en el proceso penal tienen el derecho a participar en igualdad de condiciones en las diversas fases que comprende la actividad probatoria, de conformidad con la Constitución y la ley procesal. Asimismo, se señala que los jueces están facultados para salvaguardar el principio de igualdad de armas, debiendo superar todos los escollos que obstaculicen su ejercicio. Estos resultados son consistentes con las conclusiones arribadas por Trejo (2015) en su estudio realizado, en el que concluye que la igualdad de armas es un principio que tiene por finalidad subsanar el desequilibrio real que la persecución penal persigue (pp. 304-305). De igual forma, Moratto (2021) sostiene que la igualdad de armas tiene como esencia asegurar que las partes procesales dispongan de los mismos derechos y se enfrenten a las mismas cargas, en igualdad de condiciones, sin que existan preferencias que favorezcan a una de ellas (p. 198).

Respecto al quinto objetivo específico que consistió en analizar los fundamentos que rigen el principio de igualdad de armas en el proceso penal peruano, los resultados obtenidos tanto del análisis documental como de las entrevistas, evidencian que el referido principio es una derivación del principio general de igualdad ante la ley, recogida en el artículo 2.2 de la Constitución Política del Perú. Asimismo, según Moratto (2021), el Tribunal Constitucional español ha mostrado ambigüedad cuando ha hecho referencia al principio de igualdad de armas; tal es así que en algunas de sus sentencias ha señalado que esta categoría deriva del principio de contradicción; en otras, que esta es parte del 
contenido esencial de la tutela judicial efectiva, o que forma parte del derecho a un proceso con todas las garantías; y, por último, que se deriva del derecho de defensa (p. 198).

Respecto al sexto objetivo específico que consistió en analizar la aplicabilidad del principio de igualdad de armas en el proceso penal peruano a partir de la jurisprudencia nacional, los resultados tanto de las entrevistas como del análisis de sentencias, ponen de manifiesto la necesidad de que los jueces cautelen el derecho de las partes a intervenir en el desarrollo de la actividad probatoria, sin más restricciones que las estrictamente necesarias; estando estos en armonía con los hallazgos de Díez y Vivares (2020), que en su estudio concluyeron que la normativa procesal penal colombiana garantiza el principio de igualdad de armas, en un contexto en el que se contraponen dos intereses, el del acusador privado y el de la defensa (pp. 337-338).

\section{CONSIDERACIONES FINALES}

Los principios de preclusión procesal e igualdad de armas son dos figuras jurídicas estrechamente vinculadas, dado que, en su condición de principios, comparten la misma naturaleza, es decir, son mandatos de optimización; ambos principios se encuentran regulados en el Código Procesal Penal; tienen fundamento constitucional y han sido abordados por la jurisprudencia penal de la Corte Suprema de Justicia del Perú.

El principio de preclusión procesal presenta una referencia explícita en los artículos 153, inciso 2 y 154, inciso 3 del Código Procesal Penal; asimismo, dado que esta categoría procesal se manifiesta en las fases y etapas del proceso penal, no es imprescindible que exista en la legislación procesal en forma expresa, basta que la estructura del proceso penal la origine.

El principio de preclusión procesal tiene fundamento constitucional recogido en el artículo 138 de la Constitución Política del Perú, que reconoce el principio de legalidad procesal; de igual forma, el referido principio tiene como fundamento el principio de seguridad jurídica, dado que, con esta, es posible establecer ciertos límites a la situación de incertidumbre que se origina por el ejercicio de facultades jurídico-procesales.

La Corte Suprema de Justicia del Perú ha enfatizado en la necesidad de que los actos procesales sean realizados en las fases o etapas procesales respectivas, caso contrario se extingue la facultad de realizarlos, o su realización carece de efecto alguno; en este sentido, la preclusión constituye un límite temporal para el ejercicio de facultades 
procesales, con lo que se garantiza el avance del proceso y se evita dilaciones indebidas que afectan principios como el de economía y celeridad procesal.

El principio de igualdad de armas se halla regulado en los artículos I.3 y IX.1 del Título Preliminar del Código Procesal Penal, en los que se destaca que las partes en el proceso penal tienen el derecho a participar en igualdad de condiciones en los diversos momentos que comprende la actividad probatoria; además de que los jueces están facultados para salvaguardar el referido principio, debiendo superar todos los obstáculos que dificulten su ejercicio.

El principio de igualdad de armas es una derivación del principio general de igualdad ante la ley recogido en el inciso 2 del artículo $2^{\circ}$ de la Constitución Política del Perú; asimismo, el Art. IX del Título Preliminar del Código Procesal Penal lo enmarca como parte del contenido esencial del derecho de defensa.

La Corte Suprema de Justicia del Perú, a través de su jurisprudencia, ha establecido la necesidad de que los jueces cautelen el derecho de las partes a intervenir en el desarrollo del proceso, sin más restricciones que las estrictamente necesarias; por lo que los formalismos vencibles no prevalecen sobre el derecho a la igualdad procesal, salvo que se afecten derechos de las partes.

\section{LISTA DE REFERENCIAS}

Acosta, A. F. (2018). La preclusión a partir del principio de igualdad de armas. Verba Iuris, 13(39), 123-137. https://doi.org/10.18041/0121-3474/verbaiuris.39.1321

Alvarado, A. (2018). Sistema Procesal. Garantía de la libertad. Lima, Perú: A\&C Ediciones.

Aranzamendi, L. (2015). Investigación Jurídica. $2^{\text {a }}$ edición. Lima, Perú: Editora Jurídica Grijley.

Beriain, I., \& Pérez, M. J. (2019). La inteligencia artificial en el proceso penal español: un análisis de su admisibilidad sobre la base de los derechos fundamentales implicados. Revista de Derecho UNED (25), 531-561. https://doi.org/10.5944/rduned.25.2019.27013

Bonilla-García, M. Á., \& López-Suárez, A. D. (2016). Ejemplificación del proceso metodológico de la teoría fundamentada. Cinta de moebio (57), 305-3015. http://dx.doi.org/10.4067/S0717-554X2016000300006 
Corte Suprema de Justicia del Perú (2016). Recurso de Nulidad $N^{\circ}$ 1731-2015Cajamarca. Sala Penal Transitoria. Lima: 10 de agosto de 2016.

Corte Suprema de Justicia del Perú (2017). Recurso de Nulidad N 1232-2016-Junín. Sala Penal Transitoria. Lima: 10 de enero de 2017.

Corte Suprema de Justicia del Perú (2019). Casación N 1457-2018-Nacional. Sala Penal Transitoria. Lima: 10 de junio de 2019.

Corte Suprema de Justicia del Perú (2019). Recurso de Nulidad N 1782-2018-Callao. Sala Penal Transitoria. Lima: 07 de enero de 2019.

Corte Suprema de Justicia del Perú (2020). Casación N 1618-2018-Huaura. Sala Penal Permanente. Lima: 5 de agosto de 2020.

Corte Suprema de Justicia del Perú (2020). Casación N 1839-2018-Ancash. Sala Penal Permanente. Lima: 31 de mayo de 2019.

Corte Suprema de Justicia del Perú (2020). Casación N²1-2019-Arequipa. Sala Penal Permanente. Lima: 26 de febrero de 2020.

Díez, M., \& Vivares, L. F. (2020). El acusador privado y el principio de igualdad de armas: una crítica al ordenamiento jurídico colombiano. Revista de la Facultad de Derecho y Ciencias Políticas, 50(133), 309-339. https://doi.org/10.18566/rfdcp.v50n133.a04 [visitado el 28/08/2021].

Fernández, M., Urteaga, P., \& Verona, A. (2015). Guía de investigación en Derecho. Lima: Vicerrectorado de Investigación PUCP.

Gandulfo, R. E. (2009). Sobre preclusiones procesales en el derecho chileno en tiempo de reformas: ensayo de una teoría general desde un enfoque valorativo jurídico. Ius et Praxis, 15(1), 121-189. https://dx.doi.org/10.4067/S0718$\underline{00122009000100005}$

Hernández-Sampieri, R., \& Mendoza, C. P. (2018). Metodología de la investigación: Las rutas cuantitativa, cualitativa y mixta. México: Editorial Mc Graw Hill Education.

Mercado, K. E., Perez, C. B., Castro, L. A., \& Macias, A. (2019). Estudio Cualitativo del Comportamiento del Consumidor en Compras Online. Información tecnológica, 30(1), 109-120. https://dx.doi.org/10.4067/S0718-07642019000100109 
Moratto, S. (2021). El principio de igualdad de armas: un análisis conceptual. Derecho $\begin{array}{llll}\text { Penal } & y & \text { Criminología, } & \text { 41(110), }\end{array}$ https://doi.org/10.18601/01210483.v41n110.08

Noreña, A. L., Alcaraz-Moreno, N., Rojas, J. G., \& Rebolledo-Malpica, D. (2012). Aplicabilidad de los criterios de rigor y éticos en la investigación cualitativa. Aquichan, $12(3)$, 263-274. https://www.redalyc.org/articulo.oa?id=74124948006 [visitado el 29/08/2021].

Ortiz, J. J. (2017). Sujetos procesales. (Partes, terceros e intervinientes). Ratio Juris UNAULA, 5(10), 49-63. https://doi.org/10.24142/raju.v5n10a5

Peñaranda, H. E., Quintero de Peñaranda, O., Peñaranda, H. R., \& Peñaranda, M. (2011). Sobre el Derecho Procesal en el Siglo XXI. Nómadas. Revista Crítica de $\begin{array}{lllll}\text { Ciencias } & \text { Sociales } & \text { 30(2). }\end{array}$ https://www.redalyc.org/articulo.oa?id=18120143018

Rioja, A. (2019). Constitución Política del Perú y su Jurisprudencia en nuestro Tribunal Constitucional. Lima, Perú: Jurista Editores.

Salazar, M. B., Icaza, M., \& Alejo, O. J. (2018). La importancia de la ética en la investigación. Revista Universidad y Sociedad, 10(1), 305-311. http://scielo.sld.cu/scielo.php?script=sci_arttext\&pid=S2218$\underline{36202018000100305 \& \operatorname{lng}=\mathrm{es} \& \operatorname{tn} \mathrm{ln}=\mathrm{es}}$

Santacruz, R. (2017). El principio de igualdad entre las partes en el proceso penal en México. Ciencia Jurídica, 6(11), 137-146. http://www.cienciajuridica.ugto.mx/index.php/CJ/article/view/226/208

Trejo, L. (2015). Practical problems of criminal proceedings in the light of the principle of equality of arms as a constitutional guarantee of the Accused; Problemas prácticos del proceso penal a la luz del principio de igualdad de armas como garantía constitucional del imputado. Aequitas, 9(9), 1851-5517. https://p3.usal.edu.ar/index.php/aequitas/article/view/3942

Vallines, E. (2016). Preclusión, cosa juzgada y seguridad jurídica. A vueltas con el artículo 400 de la Ley de Enjuiciamiento Civil. In Derecho, Justicia, Universidad, 3171-3195. https://eprints.ucm.es/id/eprint/48150/

Villabella, C. M. (2015). Los Métodos en la Investigación Jurídica. Algunas Precisiones. En W. A. Godínez \& J. H. García (Coordinadores), Metodologías: enseñanza e 
investigación jurídica (pp. 921-953). Instituto de Investigaciones Jurídicas UNAM. https://biblio.juridicas.unam.mx/bjv/id/3983 